\title{
TUFALARIN TAŞIMA GÜCÜNÜN FARKLI YÖNTEMLERLE BELIRLENMESİ: ANTALYA ÖRNEĞİ
}

\author{
Bayram Ali ÇELTIKK (ORCID: 0000-0003-1235-7544) \\ Ali YALÇIN(ORCID: 0000-0001-7799-6115) ${ }^{2 *}$ \\ ${ }^{1}$ BAC Mühendislik İnşaat Taah. Oto. Eml. Gida. Tar. İth. İhrt. San. Ve Tic. Ltd. Şti \\ ${ }^{2}$ Süleyman Demirel Üniv. Müh. Fak. Jeo. Müh. Böl. 32263 Isparta
}

Geliş / Received: 19.11.2018

Kabul / Accepted: 20.12.2018

\begin{abstract}
$\ddot{\mathbf{O Z Z}}$
Günümüzde başta büyük kentler olmak üzere yerleşim alanlarında farklı amaçlar doğrultusunda, mühendislik yapıları inşa edilmektedir. İnşa çalışmalarından önce mühendislik yapılarının temelini oluşturan jeolojik ortamlarda inceleme yapılmalıdır. Travertenler üzerinde bulunan Antalya'da yerleşim alanları genişlemektedir. Travertenlerin oluşumları gereği yer yer fazla pekişmemiş kesimleri tufa olarak adlandırılmaktadır. Tufalar genellikle zayıf kaya özelliği sunmakta olup karot elde etmek oldukça güçtür. Yapılan temel sondajlarında kaya kalite indisi (RQD) değerlerinin oldukça düşük olduğu gözlenmiştir. Bu çalışmada aynı seviye ve derinliklerdeki temeli oluşturan farklı özelliklerdeki traverten ve tufa seviyelerinin taşıma gücü değerleri, laboratuvarda ve arazide (yerinde) yapılan farklı deneylerle belirlenmiştir. Elde edilen bulgulara bakıldığında, laboratuvarda bulunan taşıma gücü değerleri (serbest basınç ve nokta yükleme deneyi), arazide (plaka yükleme deneyi ) elde edilen taşıma gücü değerlerine göre çok yüksek çıkmıştır. Bunun nedeni; laboratuvarda yapılan deneylerin araziye göre göreceli olarak daha sağlam örnekler üzerinde yapılmasından kaynaklanmaktadır. Tufalar gibi dayanım değerleri sık değișen jeolojik ortamlarda yerinde deneyler yapılarak taşıma gücü değerlerinin belirlenmesinin, yapıların projelendirilmesi ve güvenliği açısından uygun olacağı sonucuna varılmıştır.
\end{abstract}

Anahtar Kelimeler: Antalya, traverten, tufa, plaka yükleme, taşıma Gücü.

\section{THE DETERMINATION OF BEARING CAPACITY OF TUFAS WITH THE DIFFERENT METHODS: THE CARE OF ANTALYA}

\begin{abstract}
Nowadays, especially in big cities, engineering structures are built for different purposes in residential areas. Before construction studies, geological environments which are form the basis of engineering structures should be investigated. Antalya is one of these settlements which on travertines and the settlement areas in Antalya are expanding. Unconsolidated levels of the travertine are called as tufa. Tufas generally are weak rock properties and it is difficult to obtain cores from tufas. It was observed that rock quality index (RQD) values were quite low in the in the basement drillings. In this study, the bearing capacity values of the travertine and tufa levels of different characteristics, which form the basement at the same level and depth, were determined by different tests in the laboratory and on the field (in-situ). According to the findings obtained, the bearing capacity values obtained in the laboratory (free pressure and point loading test) were very higher the bearing capacity obtained in the field (plate loading test). The reason for this is the analysis carried out on the rocks, which are relatively stronger in the laboratory than the field. As a result, it is appropriate to determine the bearing capacity values in-situ testing in
\end{abstract}

\footnotetext{
* Corresponding author / Sorumlu yazar. email: aliyalcin@sdu.edu.tr
} 
geological environments which are strength values change frequently such as tufas, in terms of the design and safety of the structures.

Keywords: Antalya, travertine, tufa, plate loading, bearing capacity

\section{GIRIŞ}

Dünyada gelişen teknoloji ve yaşam koşullarına bağlı olarak başta büyük kentler olmak üzere yerleşim alanlarında farklı amaçlar doğrultusunda, farklı boyutlarda mühendislik yapılarının boyutları arttıkça yapı temellerinin koşulları daha da önem kazanmaktadır.

Buna rağmen inşa sırasında yapıların temelini oluşturan jeolojik ortamlarda yeterince incelemeler yapılmamaktadır. Bu çalışmada yeni yerleşime açılan ve yapılaşmanın hızlı bir şekilde devam ettiği; Antalya merkezin yaklaşık $8 \mathrm{~km}$ kuzeyde bulunan Şelale Mahallesinde temel zeminleri üzerinde incelemeler yapılmıştır [1]. (Şekil 1).

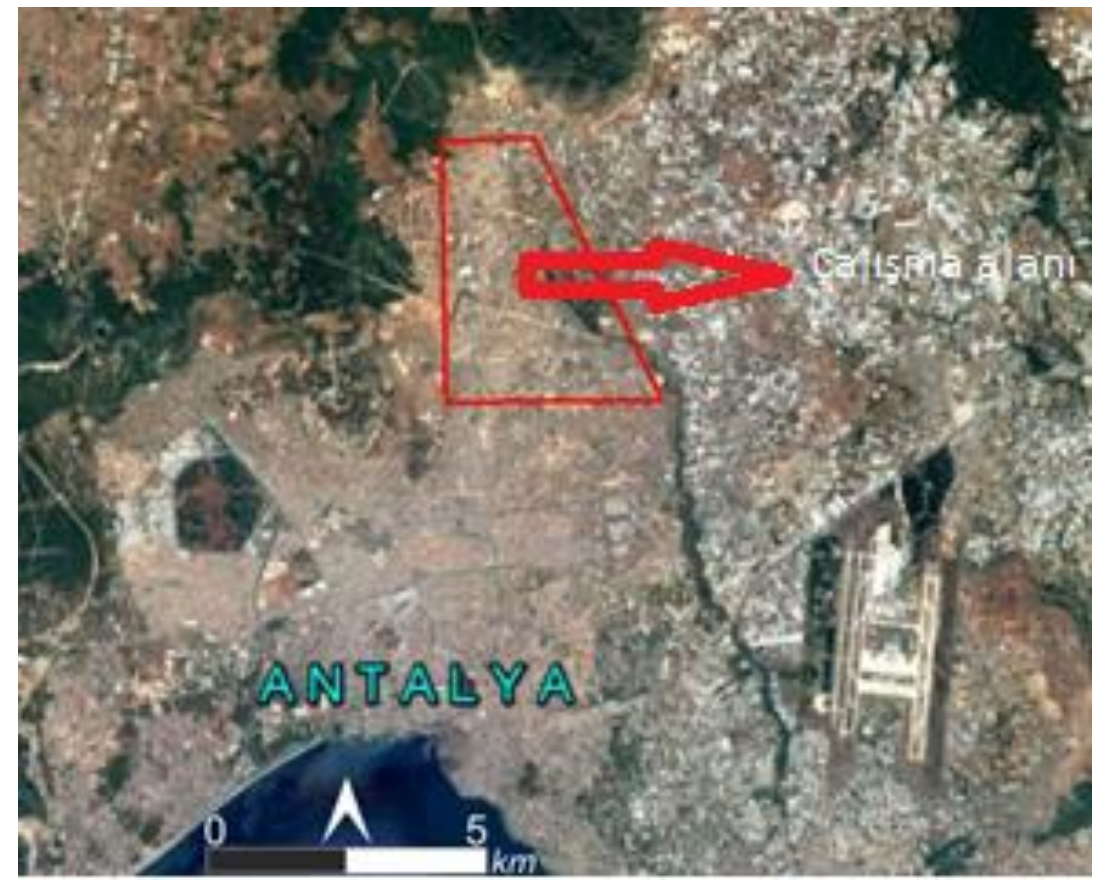

Şekil 1. Çalışma alanının konumu [1]

Antalya ili yakın civarında farklı yaş ve litolojilerden oluşan birimler yüzeylenmektedir. Bölgede çeşitli zamanlarda farklı amaçlar doğrultusunda jeolojik çalışmalar yapılmıştır. Yapılan çalışmaların değerlendirilmesi neticesinde: Antalya'nın kuzeyinde gözlenen Toroslarda, temelde otokton Jura-Kretase yaşlı Beydağları formasyonu ve üzerinde tektonik konumlu olarak Antalya Napları'nın bulunduğu belirtilmiştir. Farklı yaş ve litolojilerden oluşan Antalya Napları, alt, orta ve üst nap olarak tanımlanmıştır [2,3,4]. Tüm bu birimler üzerine uyumsuz olarak travertenler gelmektedir. Antalya yerleşim alanının üzerinde bulunduğu travertenler yaklaşık 630 $\mathrm{km}^{2}$ lik bir alan kapsamaktadır [5]. Devlet Su İşleri (DSI) 13. Bölge Müdürlügüü tarafından yapılan sondajlarda travertenlerin $254 \mathrm{~m}$ kalınlığında olduğu belirtilmiştir [6]. Kalsiyum karbonat bileşimli travertenlerdeki hâkim kalsit kristalleri aragonittir.

Antalya yerleşim biriminin üzerinde bulunduğu travertenler her yerde homojen değildir. Oluşumları gereği zayıf kaya özelliği gösteren travertenlerin fazla pekişmemiş kesimleri tufa olarak adlandırılmaktadır. Tufalar Antalya yerleşim alanı zeminini oluşturan travertenlerle ardalanmalı olarak gözlenir. Tufa olarak tanımlanan kesimler zaman zaman yüzeyde gözlendiği gibi farklı derinliklerde ve farklı kalınlıklarda gözlenmektedir. Genellikle porozitesi yüksek olan traverten ve tufalar büyük boşluklar içerirler. Boşlukların bir kısmı kil dolguludur (Şekil.3). $\mathrm{Bu}$ nedenle çalışma alanı ve yakın civarında temeli oluşturan traverten ile tufaların dayanımlarıda değişkenlik gösterir. Buna bağlı olarak mühendislik projelendirilmelerinde kullanılan taşıma gücü değerleride değişkendir. Tufalar fazla pekişmemiş oluşu ve karbonat bileşiminden dolayı suyla temasta kolayca çözünebilmektedir. Bu nedenle tufalardan karot elde etmek oldukça güçtür. Bu çalışma kapsamında Düden Şelalesi yakın civarında yapılan temel sondajlarında kaya kalite göstergesi (RQD) değerlerinin oldukça düşük olduğu gözlenmiştir.

Temellerin davranışları sadece üzerlerine etkiyen yükler ile ilgili olmayıp deprem ve su etkisi de önemlidir. Bölgedeki travertenler ve ilişkisi bulunan kireçtaşarı yeraltısuyu açısında oldukça zengindir [6]. Travertenler ve tufaların boşluklu yapısı ve su ile temasta kolayca çözünebilmesinden dolayı çökme ve deniz kıyısında devrilmeler 


\section{TUFALARIN TAŞIMA GÜCÜNÜN FARKLI YÖNTEMLERLE BELIRLENMESİ: ANTALYA ÖRNE Ğİ}

görülmektedir [7]. Bu çalışmada traverten ve tufalar üzerinde daha önce yapılan araştırmalar değerlendirilerek, tufalar üzerinde yapılan plaka yükleme deney sonuçları ile karşılaş̧ırıılmıştır.

\section{MATERYAL ve METOT}

Antalya ve yakın çevresinde farklı yaş ve litolojilerde jeolojik birimler yüzeylenmektedir. Seçilen çalışma alanı ve yakın civarı çoğunlukla travertenlerden ve bunlarla ardalanmalı tufalardan oluşmaktadır. Yerinde yapılan arazi gözlemleri sonucunda temel sondaj ve plaka yükleme deneyi yapılacak yerler seçilmiştir (Şekil 2) Çalışma alanında, toplam $75 \mathrm{~m}$ derinliğinde beş adet temel sondaj kuyusu açılmıştır. Dört noktada plaka yükleme deneyi yapılmıştır (Şekil 2). Yapılan temel sondajlardan elde edilen karot örnekler üzerinde tek eksenli basınç ve nokta yük dayanım deneyleri yapılarak taşıma gücü değerleri bulunmaya çalışılmıştır.
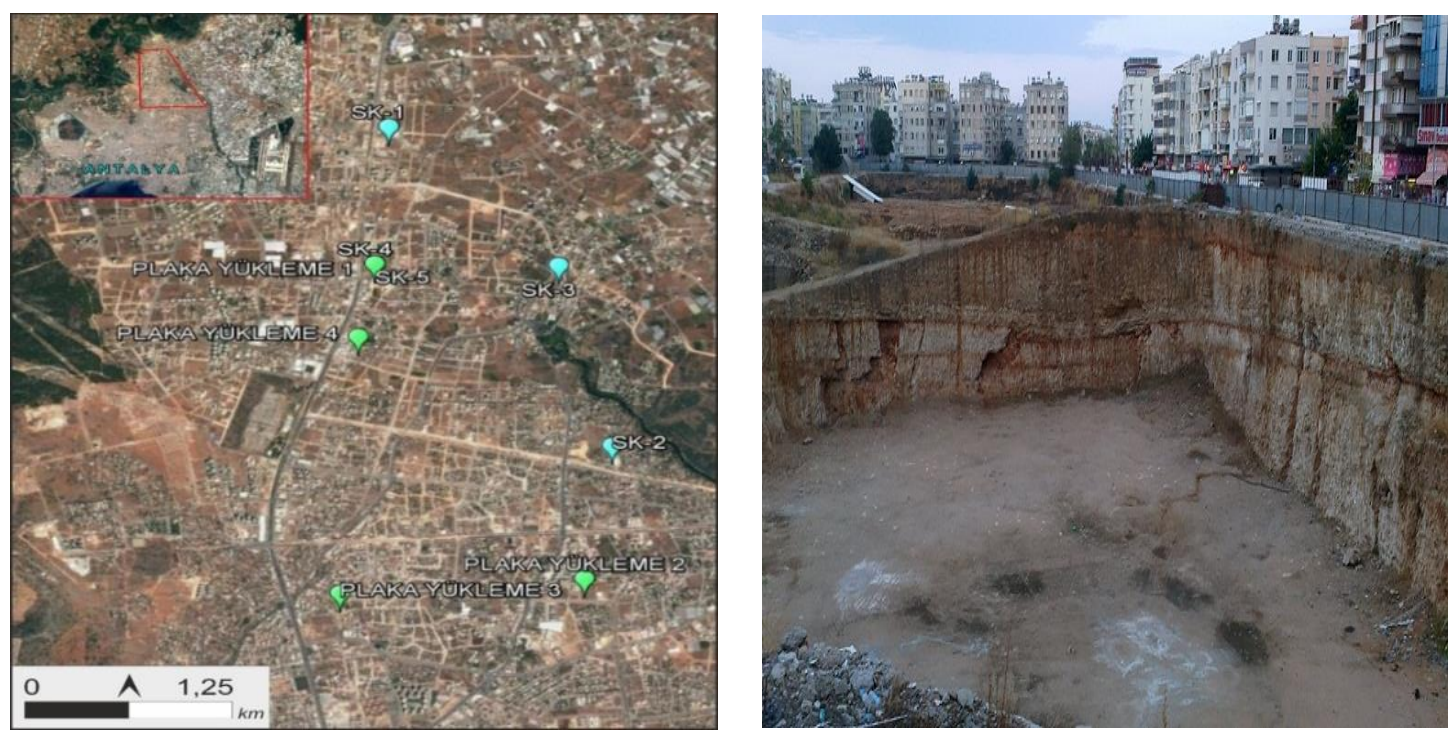

Şekil 2. Sondaj Kuyu ve Plaka Yükleme Noktaları

Şekil 3. Traverten ve tufa ardalanmasının görünümü

Plaka yükleme deneyi; çapları 30-100 cm arasında değişen daire şeklindeki plakaların belli adımlarla yüklenmesi ve her bir adımda gerçekleşen oturma miktarının kayıt edilmesi şeklinde yapılmaktadır. Uygulanan her bir yük değerinde, oturmalar stabil hale gelene kadar beklenmeli ve zemin yenilene kadar deneye devam edilmelidir. Deneyin en büyük avantajı, yatak katsayısının doğrudan ölçülebilmesidir. Buna rağmen plaka yükleme deneyi zaman alıcı ve yorucu bir deney olması nedeniyle fazla tercih edilmemektedir. Son zamanlarda kullanımı artmaktadır.

Plaka yükleme deneyi, TS 5744 (2013) standardında tanımlanmıştır [8]. Arazide yapılan plaka yükleme deneylerinde zemine normal yükün verildiği hidrolik kriko (10-20 ton kapasiteli), pompa bölümü ve piston bölümü olmak üzere iki parçadan oluşmaktadır. Dikkatli ve standardına uygun şekilde yapılan deney sonucunda deformasyon modülü (Es), yatak katsayısı (ks) ve zemin taşıma gücü (qa) belirlenmektedir.

Deneyden elde edilen veriler (Şekil 4)'de görüldüğü gibi noktalanır ve basınç-çökme eğrisinin doğruya yakın olan yani elastik kısmından herhangi iki gerilme değeri seçilir $\left(\sigma_{1}\right.$ ve $\left.\sigma_{2}\right)$. Bu gerilmelere karşılık gelen çökme değerleri $\left(S_{1 v e} S_{2}\right)$ eğriden bulunur. Ortamın seçilen bu aralıktaki Deformasyon Modülü $\left(E_{s}\right), E_{s=}$ 0,75.D. $\Delta \sigma / \Delta s$ formülü ile hesaplanır. D: plaka çapı $(\mathrm{cm}), \Delta \sigma:$ (1) ve (2) noktaları arasındaki gerilme farkı $\left(\mathrm{kg} / \mathrm{cm}^{2}\right), \Delta \mathrm{s}$ : (1) ve (2) noktaları arasındaki çökme farkı $(\mathrm{cm})$.

Plaka yükleme deneyinin belirli gerilme kademesinde, gerilmenin oturmaya oranı, yatak katsayı olarak tanımlanmaktadır. Yatak katsayısı; zeminin mümkün olan en büyük çaplı plakalar kullanılarak yapılan deneyin birinci yükleme boşaltma aşamasında hesaplanmaktadır (Şekil 5). Bu sebeple s-s eğrisinin doğruya yakın kısmı uzatılmakta ve y eksenini kestiği nokta gerçek sıfir noktası varsayılmaktadır. Bu durumda yatak katsayısı $\mathrm{Ks}=\sigma / \mathrm{s}^{\prime}$; förmülünden hesaplanır. Ks: yatak katsayısı $\left(\mathrm{kg} / \mathrm{cm}^{3}\right)$, s': seçilmiş veya önceden belirlenmiş plaka oturması $(\mathrm{cm})$, $\sigma:$ s' oturmasına karşılık gelen gerilme $\left(\mathrm{kg} / \mathrm{cm}^{2}\right)$.

Ayrıca özellikle elastik zeminlerde son taşıma gücünün yarısından daha az bir gerilmede üç kez yükleme boşaltma yapılabilir. Dolayısıyla, başlangıç (Ei), elastik teğet (Ee) ve yenilme (Ey) modülleri bulunabilmektedir. Çalışma alanında çoğunlukla ikamet amaçlı mühendislik yapıları inşa edileceğinden bu çalışmada güvenlik katsayısı $(\mathrm{F}=2)$ olarak kabul edilmiştir. 


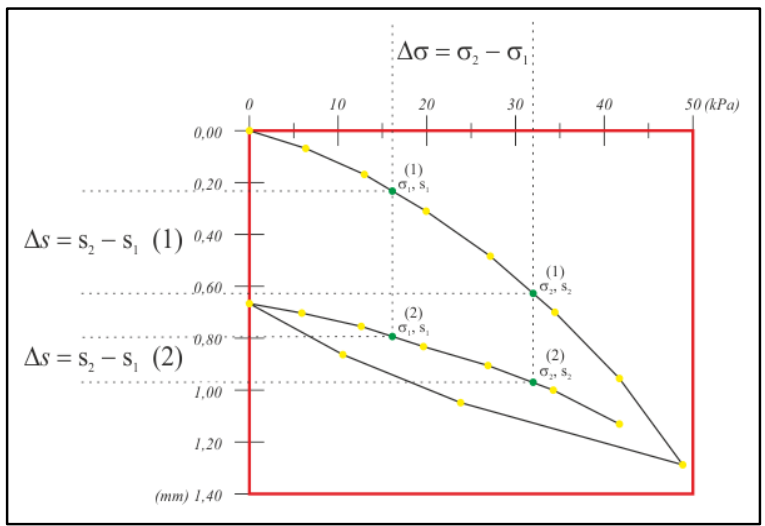

Şekil 4. Plaka Yükleme Deneyi Grafiği [8]

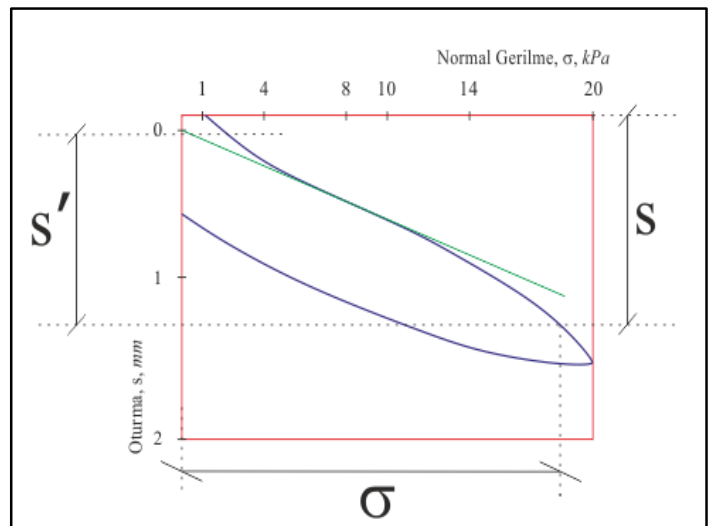

Şekil 5. Plaka Yükleme Deneyinde Yatak Katsayısı Hesabı [8]

\section{BULGULAR ve TARTIŞMA}

Arazide yapılan temel sondajlarda, travertenler ve travertenlerle ardalanmalı gözlenen tufaların bileşimi ve yapısı gereği suyla temasta çözünmesi (erimesi) sonucu karot elde etmek oldukça güçtür. Bu nedenle RQD değerleri de oldukça düşük olarak bulunmuştur. Elde edilen karotlar üzerinde; Zemin Mühendislik Jeoloji Ltd. Şti. Laboratuvarlarında ISRM [9] standartlarına uygun bir şekilde tek eksenli basınç dayanım deneyi ve nokta yük dayanım deneyleri yapılmıştır [10].

\subsection{Tek Eksenli Basınç Dayanım Deneyi}

Tek eksenli basınç dayanım deneyleri sonucunda; Dayanım değerlerinin 19,6 kgf $/ \mathrm{cm}^{2}$ ile 511,3 kgf/cm² arasında değiştiği görülmüştür. Taşıma gücü değerini belirlemek için; qa= j.qu [11] formülü kullanılmıştır. qa: Kayacın izin verilebilir taşıma basıncı $\left(\mathrm{kgf} / \mathrm{cm}^{2}\right)$, j: Kitle Faktörü, qu: Tek eksenli basınç dayanımı.

RQD değerleri ile kitle faktörü arasında bir ilişki vardır [11]. Değerlendirmeler sonucu çalışma alanındaki traverten ve tufaların taşıma gücünün $3,9 \mathrm{kgf} / \mathrm{cm}^{2}-55,7 \mathrm{kgf} / \mathrm{cm}^{2}$ arasında değiştiği belirlenmiştir.

\subsection{Nokta Yük Dayanım Deneyi}

Yapılan temel sondajlarından elde edilen karot örnekler üzerinde ASTM D5731-05 standartlarına uygun şekilde nokta yük dayanım deneyleri yapılmıştır. Deneyler sonucu (ls) değerlerinin $3,77 \mathrm{kgf} / \mathrm{cm}^{2}$ ile $29,11 \mathrm{kgf} / \mathrm{cm}^{2}$ arasında değiştiği görülmüştür. ISRM-1985'e göre yapılan düzeltmeler sonucu Is 50 değerleri belirlenmiştir. Buna göre $I_{s 50}$ değerlerinin $1,41 \mathrm{kgf} / \mathrm{cm}^{2}$ ile $11,25 \mathrm{kgf} / \mathrm{cm}^{2}$ arasında değiştiği görülmüştür. Yine ISRM 1985'e göre belirlenen $\mathrm{K}=24$ sabiti ile çarpılarak tek eksenli basınç dayanım değerleri elde edilmiştir. Buna göre tek eksenli basınç dayanımı;34,06 kgf $/ \mathrm{cm}^{2}-270,1 \mathrm{kgf} / \mathrm{cm}^{2}$ arasındadır. Daha önce tek eksenli basınç dayanımdan taşıma gücü belirlenen formül yardımıyla (qa=j.qu), taşıma gücü belirlenmiştir. Buna göre $5,11 \mathrm{kgf} / \mathrm{cm}^{2}$ ile $40,52 \mathrm{kgf} / \mathrm{cm}^{2}$ arasında değişen taşıma gücü değerleri bulunmuştur.

\subsection{Plaka Yükleme Deneyi}

Taşıma gücü daha önce detaylı bir şekilde anlatılan plaka yükleme deneyi yardımıyla da belirlenmiştir. Taşıma gücü belirlenirken qa $=\sigma / F$ förmülü kullanılmıştır. Yine daha önce belirtildiği üzere $F=2$ alınmıştır. Hesaplamalar sonucu $0,25 \mathrm{~kg} / \mathrm{cm}^{2}$ ile $3,10 \mathrm{~kg} / \mathrm{cm}^{2}$ arasında değişen değerler bulunmuştur.

Farklı yöntemlerle bulunan taşıma gücü değerleri incelendiğinde, plaka yükleme deneyi ile elde edilen taşıma gücü değerlerinin gerçeğe daha yakın olduğu görülmüştür. Bunun nedeninin laboratuvarda yapılan deney ve analizlerin göreceli olarak daha sağlam örnekler üzerinde yapılmasından kaynaklandığı sonucuna varılmıştır.

\section{SONUÇLAR}

Antalya yerleşim alanlarının taşıma gücü değerlerini elde edebilmek için çeşitli deney yöntemleri, farklı ampirik bağıntılar birçok araştırmacı tarafından önerilmiştir. Travertenlerde olduğu gibi kaya veya zayıf kaya özelliği 


\section{TUFALARIN TAŞIMA GÜCÜNÜN FARKLI YÖNTEMLERLE BELIRLENMESİ: ANTALYA ÖRNEĞ}

gösteren ortamlarda yerinde deneylerden çok laboratuvar ortamlarındaki analizlerden faydalanılarak taşıma gücü değerleri belirlenmeye çalışılmaktadır. Bu çalışmada da yapılan ve plaka yükleme deneyi sonuçları ile karşılaştırılan, tek eksenli basınç dayanım ve nokta yük dayanım değerleri dikkate alındığında taşıma gücü değerlerinin çok yüksek olduğu görülmüştür. Bu nedenle son yıllarda önemli bir uygulama alanı bulan plaka yükleme deneyi özellikle yerleşim alanındaki tufa diye nitelenen birimlerin bulunduğu bölgelerde yapılmış ve değerlendirilmiştir.

$\mathrm{Bu}$ çalışmada tek eksenli basınç dayanım deneyi sonucunda bulunan taşıma gücü değerlerinden sadece bir örnekte bulunan en düşük değer olan $3,9 \mathrm{kgf} / \mathrm{cm}^{2}$ göz ardı edildiğinde; taşıma gücü değerlerinin $21,6 \mathrm{kgf} / \mathrm{cm}^{2} \mathrm{ile}$ $67,1 \mathrm{kgf} / \mathrm{cm}^{2}$ aralığında olduğu görülmüştür. Nokta yük dayanım deneyi sonucu bulununan taşıma gücü değerleri $5,108 \mathrm{kgf} / \mathrm{cm}^{2}$ ile $40,154 \mathrm{kgf} / \mathrm{cm}^{2}$ aralığında bulunmuştur. Yerinde yapılan plaka yükleme deneyi sonuçlarına göre ise $0,25 \mathrm{kgf} / \mathrm{cm}^{2}$ ile $3,10 \mathrm{kgf} / \mathrm{cm}^{2}$ arasında taşıma gücü değerleri elde edilmiştir.

Günümüzde hızlı ve ucuz olması nedeniyle başta nokta yük dayanım indeks değeri olmak üzere tek eksenli basınç dayanım değerleri kullanılmaktadır. Bunun sonucunda Antalya'daki tufalar gibi, dayanım değerleri sık aralıklarla değişen ortamlarda gerekli özen gösterilmeden elde edilen sonuçların, mühendislik yapılarının projelendirilmesinde kullanılması neticesinde güvenli ortamlar oluşturmakta sorunlar yaşanacağı gerçektir.

Antalya yerleşim alanında kayada yapılan yerinde deneylerden presiyometre sonuçlarına ulaşılamamıştır.

Çalışmalar sırasında aynı seviye ve derinliklerdeki temeli oluşturan farklı özelliklerdeki ortamın taşıma gücü değerleri; laboratuvar ve arazide olmak üzere farklı yöntemler ile belirlenmiştir. Elde edilen bulgular değerlendirildiğinde, laboratuvarda bulunan taşıma gücü değerleri çok yüksek çıkmıştır. Bunun nedeni ise laboratuvarda arazi deneylerine göre göreceli olarak daha sağlam örnekler üzerinde yapılan analizlerdir. Tufalar gibi dayanım değerleri sık değişen jeolojik ortamlarda yerinde deneyler yapılarak taşıma gücü değerlerinin belirlenmesinin, mühendislik yapılarının projelendirilmesi ve güvenliği açısından uygun olacağı sonucuna varılmıştır.

\section{TEŞEKKÜR}

Yüksek lisans tezi olarak hazırlanan bu çalışma süresince 3860-YL 1 nolu proje kapsamında maddi destek sağlayan Süleyman Demirel Üniversitesi Bilimsel Araştırma Projeleri Yönetim Birimi Başkanlığı'na teşekkür ederiz. Çalışmalar esnasında arazi deneylerinin yapılmasında yardımlarını esirgemeyen İN-TEK Kalite Kontrol Proje Denetim Müşavirlik ve Tic. A.Ş. İle laboratuvar deneylerinin gerçekleştirildiği Zemin Mühendislik Jeoloji Ltd. Şti.'ne de teşekkür ederiz.

\section{KAYNAKLAR}

[1] http://www.hgk.msb.gov.tr/images/urun/il_ilce_alanlari.pdf// Harita Genel Komutanlığı (Erişim tarihi, 26.04.2017

[2] KALAFATÇIOĞLU, A. Antalya Körfezi Batı kısmının jeolojisi. MTA Dergisi,130,50-70,1973

[3] LEFEVRE, R., Un Nouvel Element de la Geologide du Taurus Lycien: Les Nappes d'Antalya(Turquie).C.R. Acd. Sci. Paris, ser.D, 265, 1365-1368,1967

[4] ŞENEL, M.,1:250000 ölçekli Türkiye Jeolojisi Haritaları,Antalya paftası No 3, MTA jeoloji Etütleri Dairesi, Ankara,Türkiye, 1997

[5] İNAN, N, Antalya Travertenlerinin Oluşumu ve özellikleri. Jeoloji Mühendisliği Dergisi, 24,31-37, 1985

[6] DSİ Antalya Kırkgöz Kaynakları ve Traveten platosu Karst Hidrojeolojik Etüd Raporu. DSİ Jeoteknik Hizmetler ve Yeraltı Suları Daire Başkanlığı, Ankara, Türkiye, 1985

[7] DİPOVA, N., Collapse Medhanism of The Antalya Tufa Deposits. Orta Doğu Teknik Üniversitesi, Fen Bilimleri Enstitüsü,Doktora Tezi, 1975,Ankara,Türkiye 2002

[8] GENÇ, D., Zemin Mekaniği ve Temeller. Jeoloji Mühendisleri odası yayını 100,Ankara,Türkiye,2008

[9] ISRM,Supported Method for Deterning point Load Strenoth.International Jurnal of Rock Mechanics, Mining Sciencez and Geomechanical Abstracats,22,51-60,1985

[10] ULUSAY,R., GÖKÇEOĞLU, C., BİNAL A. Kaya Mekaniği Laboratuvar Deneyleri Ders Notları 39, Hacettepe Üniversitesi yayın No 3, 535, Ankara Türkiye,1997

[11] ŞEKERCIOĞLU, E., Yapıların Projelendirilmesinde Mühendislik Jeolojisi. jeoloji Mühendisleri Odası yayınları 28,280,Ankara, Türkiye,2002 